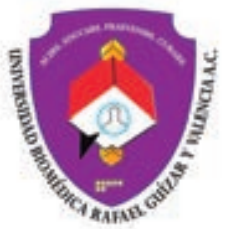

Vol. 8, Núm. 1

Enero-Junio 2021. pp. 34-38

doi: $10.35366 / 101203$

\title{
Cultural
}

\section{Xalapa y la virtud de la neblina}

\section{Xallapa and the virtue of fog}

\author{
Sergio Vásquez Vásquez, * Francisco Aguilar Rebolledo ${ }^{\ddagger}$
}

\section{RESUMEN}

Xalapa (en náhuatl: Xallapan «manantial en la arena»), oficialmente denominada Xalapa-Enríquez, es una ciudad mexicana, cabecera del municipio homónimo y capital del estado de Veracruz. Recibe los nombres de «Atenas veracruzana», por las diversas instituciones educativas y culturales que en ella se han fundado, $\mathrm{y}$ «Ciudad de las flores», denominación que Alexander von Humboldt le dio durante su visita a la ciudad en 1804. Con el murmullo citadino del vigor de una región colmada de encantos y bondades, hipnotizada acaso por la noche y su pócima de estrellas, en un devenir que va concibiendo historias ideales y tendencias, Xalapa de Enríquez, Veracruz, primitivamente Xallapan, se descubre al aire que todos respiramos y nos da vida y nos envuelve, en el sagrado misticismo de una bocanada de aire y salud, tanto para el menester de propios y extraños, íntimo y transparente, la neblina se dibuja, toca y cae por las calles asfaltadas y aun algunas empedradas. Abajo, las araucarias se cubren por su manto blanquecino, se respira humedad que la delata. Anda entre calles y callejones.

Palabras clave: Xalapa Enríquez, Veracruz, neblina, cultura, ciudad de las flores.

\begin{abstract}
Xalapa (in Nahuatl: Xallapan «spring in the sand»), officially called Xalapa-Enríquez, is a Mexican city, head of the homonymous municipality and capital of the state of Veracruz. It receives the names of "Atenas veracruzana», for the various educational and cultural institutions that have been founded in it, and «City of flowers», a name that Alexander von Humboldt gave it during his visit to the city in 1804. With the murmur city of the vigor of a region full of charms and benefits, hypnotized perhaps by the night and its potion of stars, in a future that is conceiving ideal stories and trends, Xalapa de Enríquez, Veracruz, originally Xallapan, is discovered in the air that we all breathe and it lives us and surrounds us, in the sacred mysticism of a breath of air and health, both for the needs of locals and strangers, intimate and transparent. , the mist is drawn, touches and falls through the paved streets and even some cobbled ones. Below, the araucarias are covered by their whitish mantle, humidity is breathed that gives it away. Walk between streets and alleys.
\end{abstract}

Keywords: Xalapa Enriquez, Veracruz, mist, culture, city of flowers.

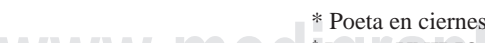 \\ ₹ Rector UNIBIO. \\ Correspondencia:}

Dr. Francisco Aguilar Rebolledo

Universidad Biomédica «Rafael Guízar y Valencia», Ángel Garrido Núm. 2,

Col. Represa del Carmen, 91050, Xalapa, Veracruz, México.

Recibido: 03-04-2021. Aceptado: 03-05-2021.

Citar como: Vásquez VS, Aguilar RF. Xalapa y la virtud de la neblina. Plast Restaur Neurol. 2021;8 (1): 34-38. https://dx.doi.org/10.35366/101203

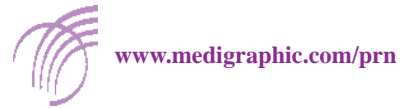




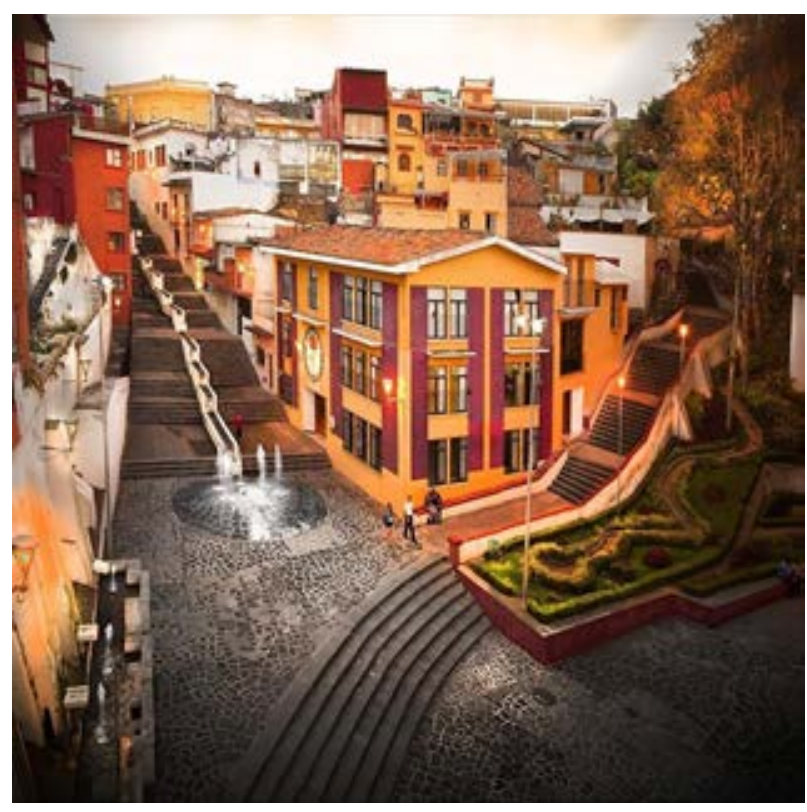

Figura 1: Xallitic.

Desde la espesura del cerro del Macuiltépelt, entre sus verdes indescifrables, en sus faldas y la planicie central hacia sus entrañas, la neblina se dibuja, toca y cae por las calles de asfalto en la ciudad y algunas empedradas.

Abajo, las araucarias se cubren por su manto blanquecino y se respira la humedad que le delata. Anda entre calles y callejones. Desciende hasta los suelos ancestrales donde otrora hubieron de conformar la ciudad del Tlalnecapan, Tecuanapan, Xallitic y Techacapan, poblados nacidos del ahínco de cuatro grupos indígenas:

1. Teochichimecas

2. Toltecas

3. Totonacas

4. Chichimecas

Los cuales sufrieron la sumisión al mandato del Imperio mexica.

Las aguas arenosas, errantes ya de caminos y hazañas, han sabido que, en el curso de los siglos, Xalapa se conserva intacta en sus historias y sus pasajes con calles de pendientes inclinadas y empedradas que sofocan al transeúnte, resplandeciendo y reflejando a contraluz al sol nuevo que le mira y la confirma (Figura 1).

La ciudad contiene en sus venas flujos de almas que han Ilevado entre sus adentros rimas, jolgorios y fiestas; arroyos que llevan nostalgias del trovador que las reinventa; en su corazón y al medio día con valor fervoroso de quienes en ella creen por su antiguo y persistente arrojo; en su alma y certeza podemos adivinar que Xalapa posee la inefable respuesta de saberse viva.

Más allá del carácter histórico en el que el extremeño Hernán Cortés y su séquito combatiente pisan por primera vez las tierras húmedas del Xallapan, el 17 de agosto de 1519, hace ya la cantidad de 502 años. Alcanza el título de Villa el 18 de diciembre de 1791, 272 años después de ser fundada. Importante en la proeza de José María Alfaro al elevar el primer globo aerostático en América desde esta ciudad el 18 de mayo de 1784. Otras fechas trascendentales en su existencia son aquellas que relatan la cotidianidad de la población, el día a día en sus calles y callejones que suben y bajan, recorriendo parques, lagos y lagunas y que en su peregrinar encuentran el aletear de las palomas, incluso el vestigio incólume de aquella abundante flora otrora de su existencia. $Y$ este nutrido caleidoscopio floral fue, de alguna manera, un buen motivo para que el Barón de Humboldt, quien la visitara todavía como Villa el 10 de Febrero de 1804, la denominara Ciudad de las Flores, ya que aquí no es intenso el calor, tampoco se siente el frío, por lo que abunda el rocío impregnado en tanta flor.

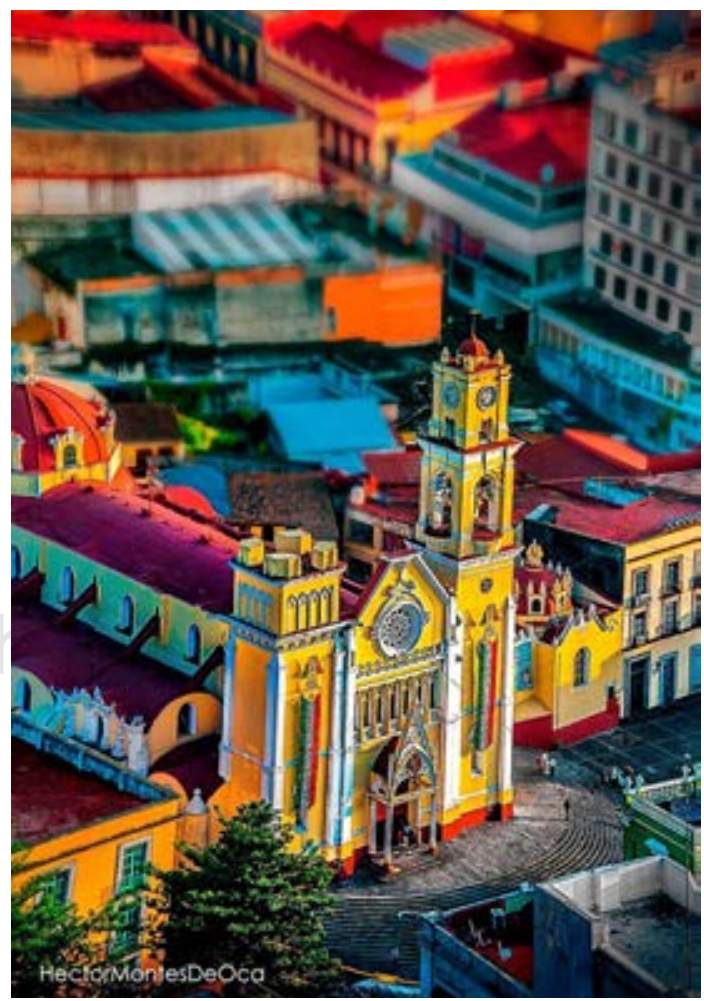

Figura 2: Calle de Enriquez. 
Sin duda, basta ser oriundo o visitante de sus tierras para elevar un fragmento de recuerdos en la esencia que se envuelve palmo a palmo en cada una de sus sinuosidades, como lo hiciese el Gral. Juan de la Luz Enríquez; un hombre sensible entre tantos, que derramó y puntualizó, desde su peculiar idealismo, los beneficios para esta hermosa ciudad al declararla como la capital Veracruzana, declarada así en el año de 1824. Quedan nombres de xalapeños desaparecidos que se pronuncian a diario, por lo que insisten en saber de Xalapa de alguna manera y cuya pertinaz existencia son el eco honrado de las acciones de estos hombres y mujeres célebres, que enorgullecen la ciudad y la hicieron suya hasta que su vida les permitió. De tal manera, que algunas calles, escuelas, edificios, parques, y hasta leyendas ostentan hoy lo que les pertenecía para siempre, en sus letras conjugándose la leyenda con el recuerdo y que permanecen hoy: Manuel R Rodríguez, Manuel Boza, Manlio Fabio Altamirano, Luis F Nachón Flandes y el cargador «Juanote», prodigio de cultura en un hombre sencillo, Enrique C Rébsamen, Domingo Alvarado y Rafael Ramírez, ejemplo para muchos y otros más (Figura 2).

Sin embargo, nuestros individuos se destacan en el legado cultural de aquellos hombres que compartieron algo de sí mismos para las futuras generaciones. Una educación propulsora se sostiene en provecho de los jóvenes para abastecerlos de la cultura necesaria para hacer frente al mundo que les toca enfrentar, pero seguros por los saberes obtenidos. Xalapa es ahora, y desde hace mucho tiempo, sede de universidades públicas y privadas que pueden proyectar a su juventud creciente a niveles nacionales e internacionales de excelencia, como la Universidad de Xalapa y la Universidad Biomédica Rafael Guízar y Valencia. Con esto, células humanas de nuestra tierra se difunden como ramas de un pródigo árbol Yaxché (o Ceiba, eje del universo de los mayas) hacia los estados de la república y los países del orbe esparciendo sus habilidades y conocimiento con orgullo veracruzano.

En Xalapa se disfruta de esa aura provinciana que además confiere, acaso paradójicamente, el desarrollo en diversos ámbitos; cierto es que se ha envuelto con solidez en la cultura (motivo por el cual se le ha denominado la «Atenas Veracruzana») como parte de una gama inmensa de manifestaciones artísticas que la distinguen como forjadora y digna contendiente de artífices originarios y aquellos que la han elegido como suya para revelar sus perspectivas plásticas y artísticas. Distintivo ejemplo es la creación de la Orquesta Sinfónica de Xalapa, en el año de
1929, que al interpretar en su primer programa la Sinfonía Inconclusa de Franz Schubert, entre otras dos melodías, avanza ininterrumpidamente a través del tiempo, y de tal manera, continúa con su trayectoria hasta el presente. Ensayando su acervo melódico en su casa original del teatro del estado, cambiando de escenario a una sala especial y trasladando sus quehaceres en el año 2013 a la Universidad Veracruzana en su propio campus; al recinto denominado «Tlaqná». Así, notas musicales, las ensayadas, las que se poetizan furtivas en una serenata, las que se guarecen precisas en la partitura mental de su creador, vuelan simultáneamente en una noche de Luna en Xalapa, sabiéndose amas del oído que las poseerá (Figura 3).

Más no son sólo tañidos los que se aprecian en esta urbe, también se hallan, en vasta amalgama, texturas, figuras, colores, letras, cantos, danzas, dramatizaciones, imágenes (las que se eternizan en un instante o las que se suceden contando largas historias visuales). El espectador de semejantes manifestaciones podrá aislarse en el tiempo, dedicado al sosiego del alma, una tarde cualquiera, una noche con neblina caminando entre sus callejones de piedra, empedrados en cautivo reflejo de las profundidades del arte en Xalapa.

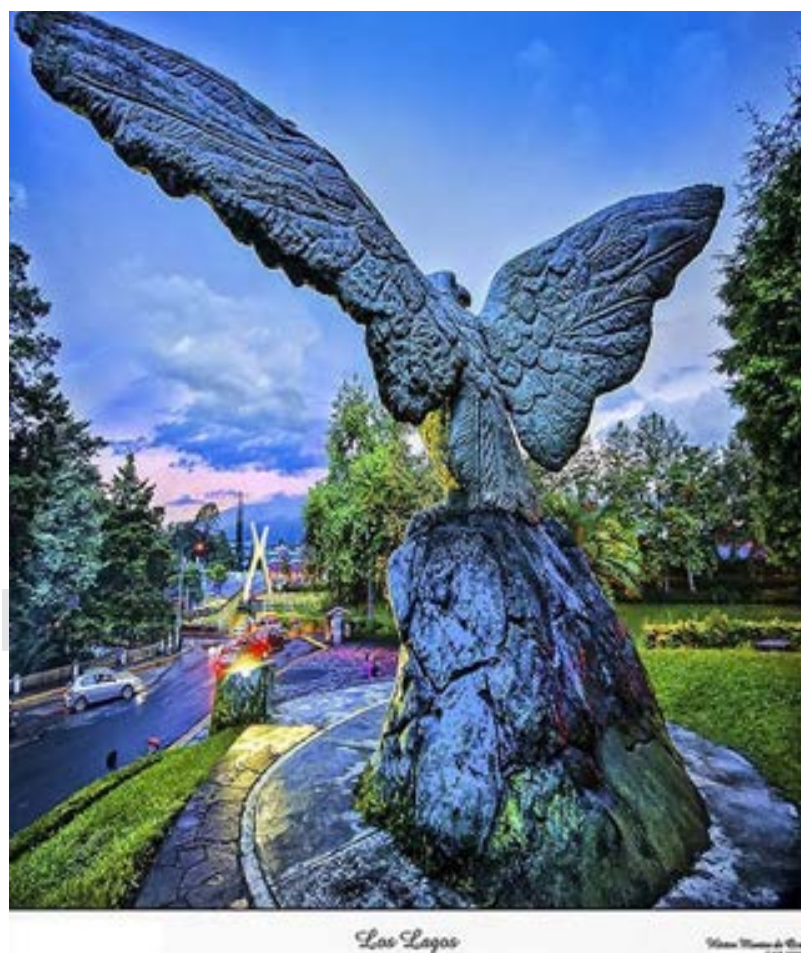

Figura 3: universidad. 


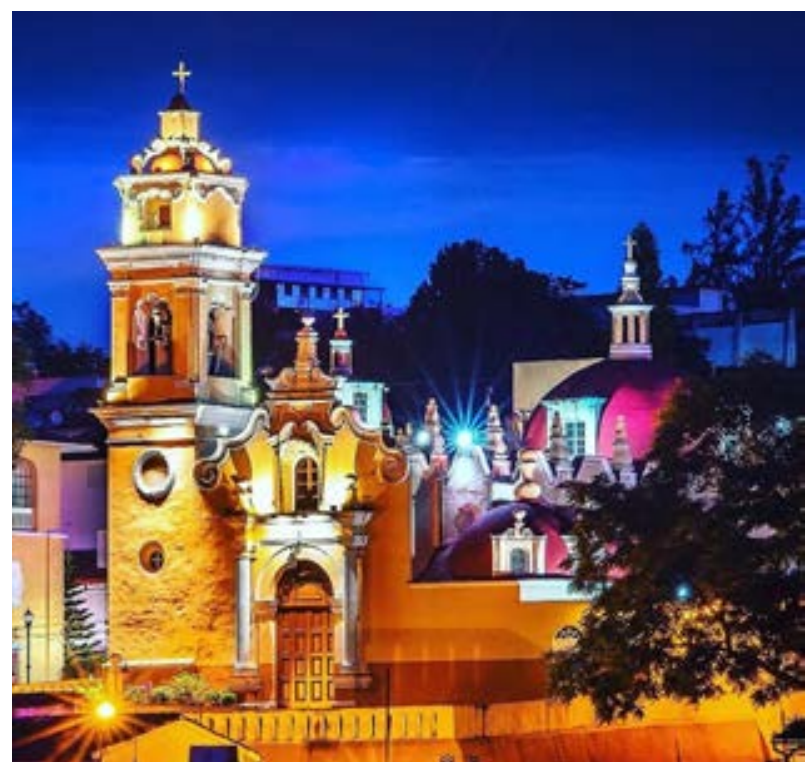

Figura 4: Parroquia de San José.

En ella, además, se concentran fantasmas como parte de las leyendas que se diversifican solas con cada palabra distinta al narrarlas, pero estos espectros son los mismos a lo que en su principio fueron, sólo que ahora esperan, a la sombra del lenguaje que los describe, el recuerdo perpetuo de sus vivencias, algunas trágicas en desenlace, como la que se cuenta del callejón del diamante, donde a manos del celoso marido muere la pérfida esposa, quien olvidara su anillo de compromiso, lucentísima prenda portadora de un diamante negro, en casa de su amante. Otro de los espacios emblemáticos lo constituye el callejón de "Jesús te ampare», ubicado cerca del barrio de San José. Aquí vivía una joven cuyo novio, llamado Cosme, la visitaba diariamente. En una aciaga noche, un borracho lo apuñaló y la joven asustada sólo pudo gritar: «Cosme, que Jesús te ampare». $\mathrm{O}$ aquellas que por el misterio circundante divagan en razones de ser, pero abren una puerta hacia el empalme muy personal de la imaginación de cada individuo que, de alguna manera, casi siempre las conoce mediante la entrega verbal de sus narradores, y sobreviven como inalterable signo de que existieron (Figura 4).

Cierto es que alrededor del Cerro de Macuiltépelt baja y se extiende, en más de 100 kilómetros cuadrados y a 1,400 metros sobre el nivel del mar, esta ciudad portentosa, ineludible a la memoria de quien la visita y aún más de quien a ella pertenece. Sus encantos naturales, entre el clima que la caracteriza en cada estación del año hasta los prodigios paisajes que puede ofrecer desde la fastuosidad de contenerse bella, inclusive la arquitectura colonial conservadora aún en varias calles del centro histórico, precede todo un contenido multiforme que empapa, desde una estética original, donde en profundidad de nuestra visión se enriquece de factores tróficos, neurotransmisores y salud en la retina.

Con el murmullo urbano del vigor de una región colmada de encantos y bondades, hipnotizada acaso por la noche y su pócima de estrellas, en un devenir que va concibiendo historias ideales y tendencias, Xalapa de Enríquez, Veracruz, primitivamente Xallapan, se descubre al aire que todos respiramos, nos da vida y nos envuelve, en el sagrado misticismo de una bocanada de aire y salud, tanto para el menester de propios y extraños, íntima y transparente.

Visitar una ciudad tan amable puede asemejarse a unas nubes, a veces delgadas, que no limitan el brillo de la ciudad ni del sol, esto nos brinda serenidad y el disfrute de la brisa transformada en neblina, transformada en salud para nuestro cuerpo y espíritu, aunque presagia tormenta.

Xalapa nos produce emociones que representan la energía motivadora de la vida y que son el combustible necesario para avanzar en nuestro propio camino de la vida, enriqueciendo las visiones a nuestro sistema nervioso, de un cerebro que sana y se renueva.

Ven a Xalapa, conoce universidades maravillosas como la UNIBIO dedicada a san Rafael Guízar y Valencia y disfruta de una ciudad donde el misticismo de las flores y la cultura nos disipan a un cerebro que sana.

Xalapa, Atenas veracruzana.

\section{...Una ciudad, un lago y una verde cordillera, que le cubre como halago la universidad con nueva era...}

Tu efluvio de cafetales refleja que del lugar se enseñorea Ahí, donde el gusto aflora en tus casas de arcilla y teja.

El frijol se cuece en leña y el café se toma en jarro de callejones halagüeña y de su juventud bizarro.

Ciudad de cuestas y valles, en tu amable arquitectura plena de historia y cultura el saber cunde en tus calles 
En la universidad histórica al igual que en tu normal se gestan, en lo universal conocimiento y retórica; pero también la poesía, que corre con algarabía por tus aceras empedradas dando al amor, pinceladas.

Y flotan por los balcones, de tus callejuelas empinadas valladares de ilusiones de parejas enamoradas.

Pensil de mujeres divinas, al numen de tus neblinas con aroma de lluvia y narciso, prendando al visitante de tu hechizo.

Francisco Aguilar Rebolledo

Agradecimientos: Dr. Héctor Montes de Oca por sus excelentes fotografías para ilustrar el artículo. 